\title{
A NOÇÃO DE EQUIVALÊNCIA PARA OS ESTUDOS DA TRADUÇÃO, LEXICOGRAFIA E SOCIOLINGUÍSTICA VARIACIONISTA
}

\author{
Valdecy de Oliveira Pontes* \\ Universidade Federal do Ceará
}

\author{
Mariana Francis** \\ Universidade do Estadual do Oeste do Paraná
}

\begin{abstract}
Resumo: Neste artigo, propomos o estudo dos significados que adquire o termo 'equivalência' dentro dos campos do conhecimento: Estudos da Tradução, Lexicografia e Sociolinguística Variacionista. A noção de equivalência é considerada de fundamental importância para as disciplinas em foco, sendo que, nas diferentes perspectivas paradigmáticas, o termo
\end{abstract}

\footnotetext{
*Valdecy de Oliveira Pontes. Possui Licenciatura Plena em Letras Português-Espanhol pela Universidade Federal do Ceará (2006), especialização em Linguística Aplicada pela Faculdade Sete de Setembro (2009), mestrado em Linguística Aplicada pela Universidade Estadual do Ceará (2009), doutorado em Linguística pela Universidade Federal do Ceará (2012) e pós-doutorado em Estudos da Tradução pela Universidade Federal de Santa Catarina (2014). É Professor Adjunto, na graduação em Letras-Espanhol e no Programa de Pós-graduação em Estudos da Tradução (POET), da Universidade Federal do Ceará. Um dos Líderes do Grupo de Pesquisas Sociolinguísticas em Língua Estrangeira (SOCIOLIN-LE - CNPQ) e pesquisador do Grupo de Pesquisas de Literatura, Tradução e suas Teorias (GELTTE-CNPQ). E-mail: valdecy.pontes@ufc.br

** Mariana Francis. Possui licenciatura em Letras Português-Espanhol (2001) e especialização em Língua, Literatura e Ensino de Língua Espanhola (2003), ambas pela Universidade Estadual do Oeste do Paraná - UNIOESTE, e mestrado em Estudos da Linguagem (2010), pela Universidade Estadual de Londrina - UEL. Doutoranda do programa de Pós-graduação em Estudos da Tradução (2013) da Universidade Federal de Santa Catarina - UFSC. Professora da UNIOESTE no campus de Foz do Iguaçu desde 2003. Contato: marianafrancis@gmail.com
} 
tem adquirido profundas variações conceituais, as quais serão analisadas no decorrer deste texto. Com o objetivo de refletir quanto a essas mudanças e aos valores atribuídos por essas áreas do saber, dentro de diferentes vertentes, trataremos, de forma contrastiva, das noções de equivalência para cada âmbito de estudo, e por fim, analisaremos as contribuições da Sociolinguística para os Estudos da Tradução e para Lexicografia no que se refere à expansão de sentidos para esses conceitos.

Palavras-chave: Equivalência. Estudos da Tradução. Lexicografia. Sociolinguística.

\title{
THE NOTION OF EQUIVALENCE FOR TRANSLATION STUDIES, LEXICOGRAPHY AND VARIATIONIST SOCIOLINGUISTICS
}

\begin{abstract}
The aim of this paper is to study the meanings that the term 'equivalence' acquires in the fields of knowledge: Translation Studies, Lexicography and Variationist Sociolinguistics. The notion of equivalence is considered of fundamental importance for the disciplines in question, because, in the different paradigmatic perspectives, the term has acquired deep conceptual variations, which will be analyzed along the text. With the purpose of reflecting upon the changes and the values attributed to these areas of knowledge, within different aspects, we will address the notions of equivalence for each area of study contratively and then analyze the contributions of Sociolinguistics to Translation Studies and Lexicography regarding the expansion of meanings for these concepts.
\end{abstract}

Keywords: Equivalence. Studies of Translation. Lexicography. Sociolinguistics.

\section{Introdução}

Parece indubitável a relação que existe entre os Estudos da Tradução, a Lexicografia e a Sociolinguística vistas as diversas formações em nível de graduação e pós-graduação, no Brasil e no exterior, que contemplam essas disciplinas na grade curricular, além dos periódicos científicos especializados que acolhem artigos sobre essas três frentes do saber humano. De forma aparentemente contraditória, como afirma Humblé (2005, p. 233), apesar de 
haver uma relação bastante evidente entre tradutor e dicionário, o número de publicações especializadas que elencam elementos desses campos do conhecimento ainda é incipiente. Pode-se dizer o mesmo quanto ao tradutor e o estudo das variantes sociolinguísticas dos idiomas pelos quais transita.

Herdeiras da tradição linguística, essas disciplinas foram ocupando espaços bem definidos no campo científico, adquirindo certa autonomia que permite estudá-las a partir dos seus próprios princípios e paradigmas. Contudo, segundo reconhece Venuti (2000, p. 5), "A translation theory always rests on particular assumptions about language use, even if they are no more than fragmentary hypotheses that remain implicit or unacknowledged" ${ }^{1}$. O mesmo se aplica aos estudos lexicográficos, embora sua relação com a linguística seja muito mais perceptível e intrínseca. A Sociolinguística, por sua vez, não é uma teoria da fala, nem o estudo do uso da língua com o propósito exclusivo de descrevê-la, mas o estudo do uso da língua no sentido de verificar o que ela revela sobre a estrutura linguística.

No que se refere especificamente ao conceito de 'equivalência', percebe-se, de forma bastante genérica, que o termo tem ocupado um lugar de destaque para os campos de conhecimento em estudo, sendo objeto de análises e debates de pesquisadores dessas áreas, sob diversas perspectivas, em diferentes contextos histórico-paradigmáticos. Com base em algumas das visões e entendimentos desses estudiosos, propõe-se olhar para essas concepções e analisar os sentidos que adquire o termo, considerando os contextos sociais de produção e recepção nos quais ele está inserido.

\section{A equivalência vista pelos Estudos da Tradução}

De forma abrangente, pode se dizer que, para os Estudos da Tradução, a equivalência consiste na base da relação entre um texto fonte, escrito num determinado idioma, e um texto alvo, escrito em outra língua para a qual o tradutor deve verter a essência do 
primeiro texto. Embora essa relação entre ambos os textos esteja determinada pelo paradigma, ou paradigmas, assumidos para a empreitada, interessa destacar, num primeiro momento, o fato de que a equivalência, para esse campo científico, implica a presença de construções textuais.

Adentrando as peculiaridades do termo, percebe-se que existem mudanças de sentido quando utilizado pelos diferentes paradigmas que norteiam as ações tradutórias. A esse respeito, Pym (2012) chama atenção para o especial cuidado que demanda a compreensão do termo 'equivalência' na área da Tradução, a fim de evitar confusões provenientes, por um lado, dos múltiplos significados que lhe são atribuídos, mas, também, dos valores atrelados a esses conceitos, para cada um dos paradigmas. Segundo esse autor:

Las teorías no son mutuamente exclusivas. Por mucho que haya malentendidos patentes entre los diversos discursos teóricos, también se producen múltiples puntos de acercamiento conceptual, a menudo ocultos bajo la confusión terminológica. Para poder identificar estos puntos es necesario analizar detalladamente los discursos teóricos: las palabras además de la historia. Así prestamos atención especial a términos como "función", "norma", "sistema" y por supuesto "equivalencia", todos los cuales varían de sentido según el marco teórico. Apuntar dichas diferencias constituye un primer paso hacia el diálogo entre los paradigmas (PYM, 2012, p. 9). ${ }^{2}$

Apontando para uma perspectiva na qual um conhecimento é construído com base em outro pré-existente, o autor alerta para os desencontros conceituais que podem ocasionar as nomenclaturas obscuras e as polifonias discursivas, e enfatiza:

Esperamos que quede evidente que uno no tiene por qué suscribirse a un solo paradigma y olvidarse de los demás, como si de un club de fútbol se tratara. Los paradigmas del 
futuro se pueden componer de fragmentos ocultos o incluso descartados de las teorías actuales (PYM, 2012, p. 11). ${ }^{3}$

Segundo aponta Menéndez (2012, p. 117) a equivalência, ou o equivalente de tradução como outros autores preferem denominá-lo, consiste em um assunto central para os Estudos da Tradução. Essa autora propõe o estudo do conceito a partir de um olhar histórico que se inicia na década de 1960, no auge dos enfoques linguísticos, e culmina no século XXI, com a ascensão dos enfoques filosófico-hermenêuticos. Nesse contexto, os sentidos de equivalência se multiplicam, adquirindo matizes conceituais e valores diferentes.

Na década de 1960, os enfoques linguísticos (paradigmas representados por estudiosos como Roman Jakobson, John Catford, Jean-Paul Vinay e Jean Dalbernet, entre outros) centravam a atenção no estudo das relações entre o texto de origem e o texto alvo à procura de paralelismos de valores em seus diversos níveis. Por exemplo, Nida (1964) defende que a equivalência excede o que seria meramente linguístico, propõe um enfoque sociolinguístico e inclui o fator contextual. O conceito de "equivalência dinâmica", proposto por Nida (1964), assenta-se na ideia de que a mensagem na língua de partida, ao ser traduzida, deveria expressar os mesmo efeitos no público alvo da língua de chegada. Nida (1964) analisa o conceito de equivalência desde a ótica de uma dicotomia entre a equivalência formal e a equivalência dinâmica. Já Catford (1980), sugeriu dois tipos de equivalência: textual e formal. A primeira diz respeito à equivalência entre o texto original e sua tradução para outra língua. A segunda, por sua vez, refere-se à equivalência de categorias gramaticais.

A partir dessa concepção de equivalência, há uma perspectiva formalista de adequação ao texto original, na qual se identifica a ideia da existência de valores iguais entre as línguas pressupondo a possibilidade de se expressar o mesmo em idiomas diferentes e desconsiderando os aspectos socioculturais. Nessa conjuntura " $L a$ equivalencia es entendida como relación absoluta y estática, una 
correspondencia uno a uno circunscripta al plano lingüístico y, por tanto, formal" (MENÉNDEZ, 2012, p. 120-121).

Por sua vez, ao iniciar o século XXI, os enfoques filosófico-hermenêuticos (cujos representantes são Paul Ricoeur, Umberto Eco, entre outros) preocupam-se com os conceitos de função, cultura e cognição. De certo ponto de vista, o significado de equivalência tradutória é deslocado para uma suposta equivalência, segundo a qual, o sentido do texto traduzido nunca é idêntico ao do texto original. Nesses enfoques tem forte apelo a ideia de tradução como negociação de sentidos e "la equivalencia es entendida como una relación funcional, relativa y dinámica” (MENÉNDEZ, 2012, p. 117)5.

Considerando os conceitos de equivalência atribuídos por uma e outra vertente histórica, a dos enfoques linguísticos e a dos enfoques filosófico-hermenêuticos, é possível destacar e comentar algumas características e particularidades, e analisá-las contrastivamente.

De modo geral, percebe-se que ambas as concepções descansam sobre a ideia de verter um texto, escrito num idioma, para outro texto, numa outra língua. Esse é o único elemento que permanece inalterado para ambas as vertentes dentre os conceitos adjudicados ao termo equivalência, sendo que todas as outras concepções consistem em qualidades opostas da relação entre o texto fonte e o texto alvo. Nos sentidos do termo, contrapõem-se os binômios: correspondência biunívoca/relação funcional; absoluta/relativa; estática/dinâmica. Em poucas décadas, o termo adquiriu, para os Estudos da Tradução, novos significados e valores opostos, dentro de enfoques diferentes, carregando em si mesmo uma verdadeira antítese conceitual.

\section{A equivalência vista pela Lexicografia}

Na Lexicografia, o termo equivalência aplica-se ao campo dos Dicionários Bilíngues (DBs). Pode se dizer, de forma genérica, que a equivalência consiste na relação estabelecida entre lexias de línguas diferentes que compartilham significados em determinados contextos. Embora verse sobre as lexias de dois idiomas, cabe sa- 
lientar, conforme afirma Bevilacqua (2006, p. 109), que todo DB é um texto, com características e singularidades próprias desse tipo de gênero textual.

Do mesmo modo que acontece com os Estudos da Tradução, o conceito de equivalência, ou equivalente de tradução, cumpre papel central para a Lexicografia Bilíngue. Percebe-se, contudo, numa perspectiva histórica, que a mudança das finalidades objetivadas pelos DBs tem propiciado a evolução do termo, o qual, de equivalente semântico em uma língua estrangeira, passa a ser entendido como um possível correspondente, contextualizado e marcado sócio-historicamente, apresentado a partir de uma visão contrastiva com a língua materna.

Apesar do uso estendido do termo entre os pesquisadores do campo lexicográfico, Werner (1982a; 1982b) alerta para a limitação do mesmo, assim como para as limitações inerentes aos DBs, pois é impossível tentar prever todas as traduções prováveis para uma lexia, em cada um dos contextos em que possa ser usada, e descrever todas as semelhanças e divergências existentes entre uma língua e a outra. Segundo o autor:

Las denominaciones de una lengua a menudo no tienen equivalencia exacta en otra lengua, o que a una denominación en una lengua le corresponden varias en otra. La diferente distribución de nombres en las distintas lenguas proviene, entre otros, del hecho de que se basan en distintas maneras de estructurar la experiencia de la realidad, de que no existe una base objetiva para la distribución de las denominaciones en una lengua (WERNER, 1982a, p. 30). ${ }^{6}$

Com base nessa observação, dentre outras, o autor afirma que o termo 'equivalência' é inadequado ao conceito, visto que, a rigor, não existe equivalência entre as estruturas linguísticas de um idioma e as de outro, e justifica seu uso no texto por ele produzido: "empleamos aquí el término ya consagrado por el uso, a pesar de 
no ser muy acertado, porque precisamente no se trata de relaciones de equivalencia" (WERNER, 1982b, p. 288) ${ }^{7}$.

Na Lexicografia Bilíngue, a mudança de sentidos do termo equivalência está vinculada às transformações ocorridas com os DBs nos últimos séculos e ao surgimento de objetivos pedagógicos a eles atrelados, no intuito de constituírem instrumentos auxiliares do ensino e da aprendizagem de línguas. Segundo apontam Duran e Xatara (2008, p. 242), até o século XIX os DBs eram objetos para a erudição, nos quais os lexicógrafos estocavam o maior número de equivalentes, além das abonações literárias, sem a preocupação do uso que o consulente daria aos mesmos.

Nesse contexto histórico, utilizava-se o método gramática-tradução para o ensino de línguas, e o objetivo centrava-se na leitura, tradução e análise de textos literários. Na aproximação com a língua estrangeira, o aluno deveria reconhecer as palavras ou consultá-las nos dicionários a fim de escolher o equivalente que considerasse mais adequado ao contexto exposto. As poucas informações oferecidas por essas obras tornavam a tarefa complexa, sendo que o sentido de equivalência estava limitado aos aspectos semânticos das correspondências entre as línguas.

Com a popularização do ensino de línguas, no século $\mathrm{XX}$, e o surgimento de diferentes enfoques e métodos de ensino, os DBs foram se adaptando ao novo objetivo de uso, surgindo versões menores das obras consagradas e, aos poucos, modificando a forma e o tipo de informações oferecidas.

Nessa conjuntura, o equivalente passa a compartilhar espaço com uma série de outros dados que auxiliam um uso mais apurado da língua estrangeira nas diversas situações e contextos. Em especial, a partir da década de 1970, com a ascensão do enfoque comunicativo, "começou-se a pensar para quem e para que fazer [dicionários]. O aprendiz de língua estrangeira [...] acabou inspirando muitas inovações nos dicionários" (DURAN, XATARA, 2008, p. 244).

Mas é na década de 1990 que os estudos do léxico abrem espaço para uma visão mais ampla da equivalência. O uso da Linguística de Corpus, aplicado a projetos lexicográficos, promove a compara- 
ção entre a língua materna e a língua estrangeira, dentro de diferentes contextos reais de utilização dos idiomas, e, também, promove a tradução de blocos de significados. Nesse âmbito, a equivalência se reafirma como um possível correspondente, contextualizado e marcado cultural e sócio-historicamente.

Tendo em vista os sentidos intrínsecos ao termo 'equivalência' nesses dois momentos da evolução lexicográfica, permeados pelas ideias de dois enfoques para o ensino de línguas, o da gramática-tradução e o comunicativo, são perceptíveis alguns aspectos quanto à mudança de conceituação que merecem destaque. Embora em ambas as abordagens o DB cumpra um papel relevante para a aprendizagem de línguas, o que implica em certa abstração do léxico do seu contexto de uso a fim de analisá-lo e compreende-lo, no primeiro enfoque a equivalência atua dentro de um sistema linguístico ideal e normativo, o da língua literária, enquanto no segundo enfoque procuram-se situações reais de uso em ambas as línguas.

Outro aspecto a ser observado é o papel do consulente, o qual passa a ter relevância dentro do enfoque comunicativo, promovendo a elaboração de DBs mais adequados a suas necessidades, que possuam informações mais amplas e relevantes sobre as relações de equivalência entre as línguas, de forma contrastiva, nas suas diversas formas de expressão. Nesse sentido, a ideia de equivalência está circunscrita às noções de diversidade, dinamismo e relativismo linguístico, as quais estão em franca oposição aos conceitos atrelados ao termo dentro do enfoque da gramática-tradução, para o qual a equivalência é entendida como algo absoluto, estático e normativo.

\section{A equivalência vista pela Sociolinguística Variacionista}

A Sociolinguística estuda a língua a partir do seu contexto social, com o objetivo de descrever como fatores linguísticos e extralinguísticos influenciam os fenômenos de variação e mudança inerentes às línguas. Os primeiros estudos da Sociolinguística Variacionista surgiram na década de 1960 , como reação à corrente 
linguística proposta por Chomsky na década de 1950 - a gramática gerativa, cujo objeto de estudo é a competência de um falante-ouvinte ideal pertencente a uma comunidade linguística homogênea. Segundo Bagno (2007), a Sociolinguística surgiu porque muitos cientistas nos Estados Unidos perceberam que não era possível estudar a língua desconsiderando a sociedade em que é falada, pois a língua não é homogênea e estável, mas está em constante mudança devido às interações sociais. O estudo da variação a que nos ateremos foi impulsionado por William Labov, cujo modelo se apresenta como reação à ausência do componente social no modelo gerativo e à homogeneidade e autonomia preconizadas pelo Estruturalismo. Labov (1972) diverge de Saussure e de Chomsky propondo o estudo da estrutura e da evolução da língua no contexto social da comunidade. Segundo Figueroa (1996, p. 71), quando se diz que a Sociolinguística é o estudo da língua em seu contexto social, isso não deve ser mal-interpretado. A Sociolinguística laboviana não é uma teoria da fala, nem o estudo do uso da língua com o propósito exclusivo de descrevê-la, mas o estudo do uso da língua no sentido de verificar o que ela revela sobre a estrutura linguística.

No que tange ao conceito de equivalência para a Sociolinguística Variacionista, de acordo com Labov (1978), as variantes constituem os diversos modos de se dizer a mesma coisa, ou seja, remeter ao mesmo estado de coisas, em um mesmo contexto de interação verbal. Os primeiros trabalhos de análise sociolinguística $^{8}$, que se concentravam no âmbito da Fonologia, evidenciaram que diferentes formas de comunicar, que compartilham o mesmo valor de verdade, apresentam diferenças no tocante aos valores sociais e estilísticos. Esse fato dá abertura a críticas em relação à manutenção do mesmo significado pelas variantes de uma mesma regra variável, questionamento explicitado em artigo por Lavandera $(1978)^{9}$, que afirma que cada construção sintática possui seu significado próprio, sendo complicado substituir uma forma sintática por outra preservando o mesmo valor de verdade. Para a autora, o estudo sobre a variação linguística fora do âmbito da Fonologia fica comprometido, pois nem sempre há consenso 
sobre o valor de verdade das variantes analisadas. Propõe que a condição de mesmo significado seja ampliada para o que chama de comparabilidade funcional, na qual a existência, em um mesmo espaço, de formas alternantes ou a troca de uma forma por outra com o mesmo significado referencial não são livres e nem totalmente condicionadas por fatores extralinguísticos, mas refletem uma escolha funcional tendo em vista os propósitos comunicativos. Lavandera (1978) critica, também, o fato de que muitas formas que estão fora do campo fonológico não sofrem influências sociais ou estilísticas, apenas linguísticas. Por exemplo, a substituição de construções passivas por ativas, no mesmo contexto e com o mesmo significado.

Para responder o questionamento levantado por Lavandera (1978) sobre os limites da variável sociolinguística, Labov (1978, p.02) afirma que são variantes os enunciados que possuem o mesmo significado referencial, ou seja, o mesmo significado representacional ou estado de coisas: "dois enunciados que se referem ao mesmo estado de coisas têm o mesmo valor de verdade". O autor ratifica o princípio da equivalência semântica e destaca ser necessário que, como variantes de uma variável, se aceitem enunciados que possuam o mesmo valor de verdade, no mesmo contexto, mas não rigorosamente o mesmo significado. Seguindo essa lógica, pode haver diferenças em matizes de sentido, desde que o significado referencial não seja afetado. Labov (1978) separa o significado referencial em um nível, considerado como primário, e as funções de identificação do falante e de acomodação do ouvinte em outro nível (secundário) que contemplaria os aspectos sociais e estilísticos. Dessa forma, variantes que portam diferenças de cunho pragmático, podem ter o mesmo significado referencial. Labov (1978) argumenta, ainda, que a Sociolinguística é "sócio" não só porque lida com fatores estilísticos e sociais, mas por analisar a língua como componente social.

Ao verificarmos o funcionamento de uma língua, percebemos que, nos diferentes contextos, ela apresenta-se de forma heterogênea, ou seja, apresenta variações. Tarallo (2005), retomando a pro- 
posta de Coseriu $^{10}$ (1976 [1968]), apresenta essas variações como: diatópicas (diferenças em função do espaço geográfico); diastráticas (diferenças em função dos aspectos sociais como sexo, idade, etnia etc.) e diafásicas (diferenças em função da utilização dos diversos estilos de linguagem na comunicação). Partindo do pressuposto de que a variação linguística é inerente a qualquer língua, julgamos de vital importância que a Lexicografia e os Estudos da Tradução a considerem para a construção de sentidos mais amplos atrelados ao conceito, ou conceitos, de 'equivalência'.

\section{Contribuições da Sociolinguística Variacionista para os Estudos da Tradução e para a Lexicografia: ampliando sentidos para os conceitos de 'equivalência'}

Se traçarmos um paralelo com o desenvolvimento dos Estudos da Tradução e da Lexicografia, a Sociolinguística surgirá como subárea da Linguística, numa fase na qual os estudos de cunho estritamente formal passaram a ser questionados e a língua passou a ser analisada, também, a partir do contexto pragmático-discursivo, em uma perspectiva funcionalista da linguagem. No mesmo período, a Lexicografia amplia o seu conceito de equivalência e, ao comparar a língua materna e a língua estrangeira, passa a considerar os contextos reais de uso. Os Estudos da Tradução, por sua vez, também, procuram inserir o contexto sócio-histórico no processo tradutório, Oliveira (2007).

No tocante à busca por equivalentes entre a língua de chegada e a língua de partida, vários autores ressaltam a importância da variação linguística. Lefevere (1992) destaca o papel da variedade linguística para a tradução de uma situação específica, nas diferentes culturas. Venuti (2000) enfatiza os valores culturais e políticos que consolidam a prática e a investigação tradutológica, e reconhece, de forma explícita, a importância da recuperação da variação sociolinguística no texto a ser traduzido. Segundo Agra (2007), traduzir não se reduz a uma atividade mecânica de transcodificação 
linguística, mas se trata de "desvendar" e interpretar o que está "por de trás" de uma palavra inserida num determinado contexto sociocultural e que sentidos esse vocábulo adquire nessa cultura. A autora destaca, ainda, que uma palavra tem seus significados socialmente construídos e que o tradutor deve considerar essa variável tão relevante e decisiva no processo tradutório. Snell-Hornby $(1988,1995)$ pontua a necessidade de que exista um fundo sociocultural na atividade tradutora e que o enfoque seja interdisciplinar com um lugar específico para a Sociolinguística. Para traduzir, é de vital importância interpretar e analisar não somente as estruturas lexicais e morfossintáticas como também o contexto pragmático-discursivo que configura o pano de fundo do texto a ser traduzido. Desse modo, uma análise sociolinguística poderá contribuir para a ampliação do conhecimento no que tange ao contexto em que o texto foi escrito.

As variedades de uma língua constituem uma abstração que pertence ao contexto pragmático-discursivo de cada comunidade de fala de cada região e não ao mundo material dos textos originais ou traduzidos. Nesse sentido, segundo Mayoral (1998), o tradutor traduz textos específicos com marcas sociolinguísticas ou, ainda, de situações específicas, esta tradução se ajusta a um encargo específico e as exigências gerais da eficácia da comunicação para que o receptor possa compreender o contexto situacional traduzido de uma língua para outra.

$\mathrm{Na}$ atividade tradutória, os encargos e os eventos comunicativos são únicos e estão submetidos a condicionamentos linguísticos e extralingüísticos; $\log 0$, o tradutor deve estar atento às influências sócio-linguístico-culturais de uma sociedade sobre a teoria e a prática da tradução, considerando os processos de variação e mudança linguísticas. Para o tradutor, a(s) língua(s) que falam as pessoas, que intervêm em um processo de interação verbal, presentes em um texto oral ou escrito a ser traduzido, não constituem apenas um elemento do contexto situacional a ser traduzido, mas, também, um meio de diferenciação social, regional, étnica ou geográfica, e inclusive sexual em alguns casos, que lhe permitirão adotar determi- 
nadas estratégias, no momento de realizar a tradução da mensagem que se deseja transmitir.

Nesse sentido, o tradutor não pode estar alheio a esse complexo panorama de diversidade linguística, mas deve encarar a língua com suas diversas variedades. Logo, o tradutor deve saber que existe uma variedade em toda língua que se denomina norma estándar ou padrão, que está associada à ideia de língua homogênea descrita/ prescrita pela gramática normativa. Essa variedade da língua tem um papel unificador e busca neutralizar as variações tornando-se uma "referência suprarregional", conforme Faraco (2002, p.42). Ela é utilizada em situações de caráter mais formal, essa variedade tem prestígio e é reconhecida como a variedade linguística que se utiliza nos meios de comunicação de difusão nacional, na escola e no ensino de línguas para estrangeiros.

Certos tipos de textos, como os científicos, geralmente, utilizam a variedade escrita e oral do estándar (quase neutra) com uma clara marcação do campo de saber respectivo, mediante o uso de um tecnoleto (língua específica da área de estudo). Por outro lado, outros textos, como os literários ou, ainda, filmes e novelas a serem dublados ou legendados para outra língua, podem apresentar os recursos expressivos (dialetais, socioletais, estilísticos, etc.) de uma variedade não-padrão da língua, em clara oposição à pretendida neutralidade da norma padrão ou estándar. Nesse caso, o tradutor deve considerar as normas linguísticas dos grupos sociais dos quais os indivíduos, que interagem em situações reportadas pelo texto a ser traduzido, participam, pois eles apresentam características identitárias por se agregarem a certos valores socioculturais, e, ademais, mesclam-se e se influenciam mutuamente, ou seja, são mesclados ou "hibridizados", conforme Faraco (2002, p. 39).

\section{Considerações finais}

Após haver analisado alguns dos sentidos que adquiriu o termo 'equivalência' para os Estudos da Tradução e para a Lexicogra- 
fia, fica bastante evidente a transformação conceitual que o mesmo tem apresentado, dentro de uma e outra disciplina, nas diferentes perspectivas e paradigmas abordados neste estudo. Para cada uma dessas áreas, as noções de equivalência têm se ampliado consideravelmente, adotando perspectivas mais abrangentes quanto às formas de dimensionar os elementos constitutivos desses saberes e as formas de abordá-los e discuti-los.

Embora a palavra equivalência, ao ser adotada por um e outro campo do conhecimento, esteja restringida à condição de termo, cada área do saber a entenderá e utilizará desde sua própria dimensão científica. Isso implica que existem, na verdade, dois termos para a mesma palavra, ou seja, existe um termo 'equivalência' que só se aplica para os Estudos da Tradução, e outro termo de idêntica morfologia ('equivalência') usado na Lexicografia. Cada um desses termos, entretanto, poderá atuar, apenas, no seu próprio território. Percebe-se, além disso, que ambos os termos mantém certo grau de simetria nas suas mudanças de sentidos, pelos diversos significados que adquirem tanto nos Estudos da Tradução quanto na Lexicografia, perfazendo caminhos evolutivos na construção conceitual que, diacronicamente, se direcionam para uma visão mais flexível, dinâmica e funcional da comunicação interlínguas.

Por sua vez, a Sociolinguística Variacionista entende o termo equivalência sob uma perspectiva diferente, porém, complementária, pois parte do pressuposto de que, ao analisar possíveis correspondências entre palavras supostamente equivalentes, o tradutor deve considerar aspectos de diferenciação social, regional, étnica, geográfica, sexual, ou situacional para que possa realizar os ajustes necessários durante o processo de tradução do texto em questão para a língua de chegada, já que, no olhar dessa disciplina científica, não há correspondência 'perfeita' entre as línguas. 


\section{Notas}

1. "A teoria da tradução sempre repousa em pressupostos específicos sobre o uso da linguagem, mesmo que esses consistam apenas de hipóteses fragmentárias que permanecem implícitas ou desconhecidas" (VENUTI, 2000, p.5, tradução nossa).

2. "As teorias não são mutuamente exclusivas. A pesar de haver mal-entendidos aparentes entre os diversos discursos teóricos, também se produzem múltiplos pontos de aproximação conceitual, muitas vezes ocultos sob a confusão terminológica. Para poder identificar esses pontos é necessário analisar detalhadamente os discursos teóricos: além da história, também as palavras. Dessa forma, prestamos atenção especial a termos como "função", "norma", "sistema" e, é claro, "equivalência", todos os quais variam de sentido segundo o marco teórico. Apontar essas diferenças constitui um primeiro passo para o diálogo entre os paradigmas" (PYM, 2012, p. 9, tradução nossa).

3. "Esperamos que fique evidente o fato de não haver um motivo para subscrever-se a um só paradigma e esquecer os outros, como se tratasse de um clube de futebol. Os paradigmas do futuro poderão ser compostos de fragmentos ocultos, ou inclusive descartados, das teorias atuais" (PYM, 2012, p. 11, tradução nossa).

4. "A equivalência é entendida como relação absoluta e estática, uma correspondência um a um circunscrita ao plano linguístico e, portanto, formal" (MENÉNDEZ, 2012, p. 120-121, tradução nossa).

5. "a equivalência é entendida como una relação funcional, relativa e dinâmica" (MENÉNDEZ, 2012, p. 117, tradução nossa).

6. "Frequentemente, as denominações de uma língua não têm equivalência exata em outra língua, ou seja, a uma denominação numa língua lhe correspondem várias em outra. A distribuição desigual de nomes nas diferentes línguas provém, entre outros motivos, do fato de que se baseiam em diferentes maneiras de estruturar a experiência da realidade, de que no existe una base objetiva para a distribuição das denominações numa língua" (WERNER, 1982a, p. 30, tradução nossa).

7. "empregamos aqui o termo já consagrado pelo uso, apesar de não ser muito acertado, porque, precisamente, não se trata de relações de equivalência" (WERNER, 1982b, p. 288, tradução nossa). 
8. Estudos desenvolvidos por Labov na década de 1960, primeiramente na ilha de Martha's Vineyard, em 1963, e, depois, na cidade de Nova York, em 1966.

9. García (1985), Milroy e Gordon (2003), também, questionaram o estatuto teórico da regra variável, no estudo de fenômenos de variação para além da Fonologia.

10. De acordo com o modelo tricotômico (arquitectura da língua) de Eugênio Coseriu (1976 [1968]), as variações da língua são de natureza diatópica, diastrática e diafásica.

\section{Referências}

AGRA, Klondy Lúcia de Oliveira. A integração da língua e da cultura no processo de tradução. Biblioteca Online de Ciências da Comunicação, 2007. Disponível em: <www.bocc.ubi.pt/pag/agra-klondy-integracao da lingua.pdf > . Acesso em: 18 mar. 2013.

BAGNO, M. Nada na língua é por acaso: por uma pedagogia da variação linguística. São Paulo: Parábola, 2007.

BEVILACQUA, Cleci Regina. Lexicografia bilíngue: aspectos teóricos e reflexões sobre os dicionários bilíngues português-espanhol e espanhol-português. In: ROTTAVA, Lucia; SANTOS, Sulany Silveira dos (Org.). Ensino e aprendizagem de línguas: língua estrangeira. Ijuí: Unijuí, 2006, p. 107-138.

CATFORD, John C. Uma teoria linguística da tradução: um ensaio em linguística aplicada. Tradução do Centro de Especialização de Tradutores de Inglês do Instituto de Letras da Pontifícia Universidade Católica de Campinas. São Paulo: Cultrix / Campinas: Pontifícia Universidade Católica de Campinas, 1980. 
COSERIU, E. Perspectivas Gerais [1968]. In: NARO, A. J. (Org.). Tendências Atuais da Linguística e da Filologia no Brasil. Rio de Janeiro: Editora Francisco Alves, 1976. p. 11-40.

DURAN, Magali Sanches; XATARA, Claudia Maria. Reflexos da evolução do ensino de línguas na lexicografia bilíngue. Trabalhos em Linguística Aplicada, Campinas, v. 1, n. 47, p. 241-250, 2008.

FARACO, Carlos Alberto. Norma-padrão brasileira: desembaraçando alguns nós. In: BAGNO, Marcos (Org.). A linguística da norma. São Paulo: Loyola, 2002. p. 37-61.

FIGUEROA, E. Sociolinguistic Metatheory. Language \& Communication Library. Vol. 14. Oxford: Pergamom, 1996.

GARCÍA, E. C. Shifting Variation. Lingua, v.67, p. 189-224, 1985.

HUMBLÉ, Philippe. O estudo da tradução e os dicionários. Trabalhos em Linguística Aplicada, Campinas, v. 44, n. 2, p. 233-246, 2005.

LABOV, W. Sociolinguistic patterns. Philadelphia: University of Pennsylvania Press, 1972.

. Where does the Linguistic variable stop? A response to Beatriz Lavandera. Texas Working Papers in Sociolinguistics, v. 44, Texas, 1978.

LAVANDERA, B. Where Does de Sociolinguistics Variable Stop? Language in Society, v. 7, p. 171-182, 1978.

LEFEVERE, A. Translating Literature Practice and Theory in a Comparative Literature Context. Nova York: MLA, 1992.

MAYORAL, Roberto. La traducción de la variación lingüística. 1998. [Tesis doctoral]. Universidad de Granada, Granada, 1998.

MENÉNDEZ, Marina N. El concepto de equivalencia. In: CAGNOLATI, Beatriz E. (Comp.). La traductología: miradas para comprender su complejidad. La 
Plata: Universidad Nacional de La Plata / Facultad de Humanidades y Ciencias de la Educación, 2012. p. 117-187.

MILROY, L.; GORDON, M. Sociolinguistics: method and interpretation. Oxford: Blackwell, 2003.

NIDA, Eugene. Toward a Science of Translation. Leiden: E. J. Brill, 1964.

OLIVEIRA, Alessandra Ramos. Equivalência: sinônimo de divergência. Cadernos de Tradução (UFSC), Florianópolis, n.19, p. 97-114, 2007.

PYM, Anthony. Teorías contemporáneas de la traducción: materiales para un curso universitario. Tarragona: Intercultural Studies Group, 2012. Disponível em: < http://isg.urv.es/publicity/isg/publications/2011_teorias/pym_teorias_traduccion_web.pdf $>$. Acesso em: 20 nov. 2013.

SNELL-HORNBY, M. Translation Studies: an Integrated Approach. Amsterdam: John Benjamins Publishing Company / Philadelphia, 1988/1995.

TARAllo, F. A Pesquisa Sociolinguística. 7ª ed. São Paulo: Ática, 2005.

VENUTI, Lawrence. The Translation studies reader. London: Routledge, 2000.

WERNER, Reinhold. Léxico y teoría general del lenguaje. In: HAENSCH, Günther; WOLF, Lothar; ETTINGER, Stefan; WERNER, Reinhold. La lexicografia: de la lingüística teórica a la lexicografía práctica. Madrid: Gredos, 1982. p. 21-94.

. La definición lexicográfica. In: HAENSCH, Günther; WOLF, Lothar; ETTINGER, Stefan; WERNER, Reinhold. La lexicografia: de la lingüística teórica a la lexicografía práctica. Madrid: Gredos, 1982. p. 259-328.

Recebido: 06-01-14

Aceito: 20-03-14 